\title{
O CONSENTIMENTO INFORMADO E SUA DINÂMICA NA RELAÇÃO MÉDICO- PACIENTE: NATUREZA JURÍDICA, ESTRUTURA E CRISE
}

\author{
THE INFORMED CONSENT AND ITS DYNAMICS IN THE DOCTOR-PATIENT \\ RELATIONSHIP: LEGAL NATURE, STRUCTURE AND CRISIS
}

Silvio Romero Beltrão*

\begin{abstract}
RESUMO: O presente trabalho tem o caráter interdisciplinar e pretende analisar a dinâmica do consentimento informado, além de sua estrutura jurídica formal, apresentando inicialmente a existência de conflitos entre a autonomia do paciente e o dever do médico, diante da existência de uma crise que dificulta a aplicação precisa do consentimento informado na prática. O presente estudo foi concebido com base na doutrina portuguesa e brasileira, tendo como ponto de partida a análise da natureza jurídica da relação médico-paciente, para em seguida verificar a valoração da autonomia da vontade do paciente como estrutura nuclear da relação jurídica médico-paciente. Define o consentimento informado e sua estrutura e demonstra que o mesmo se encontra em crise. Expõe os requisitos do consentimento informado e aponta ao fim à necessidade do estudo dos diversos fatores que influenciam a correta aplicação do consentimento informado.
\end{abstract}

PALAVRAS-CHAVE: Consentimento Informado; Médicopaciente; Vontade; Estudos comparativos Brasil-Portugal.
ABSTRACT: This paper has an interdisciplinary character and intends to analyze the dynamics of informed consent, beyond its formal legal structure, initially presenting the existence of conflicts between the patient autonomy and the duty of the doctor, in face of the existence of a crisis that hampers the precise application of the informed consent in practice. The present study was designed based on Portuguese and Brazilian doctrine, having as its starting point the analysis of the legal nature of the doctor-patient relationship, in order to then verify the valuation of the patient's autonomy of the will as core structure of the doctor-patient legal relationship. It is defined the informed consent and its structure and it is demonstrated that such institute is in crisis. It is outlined the requirements of informed consent and points to, finally, for the need to study the various factors that influence the correct application of informed consent.

KEYWORDS: Informed Consent; Doctor-Patient; Will; BrazilPortugal Comparative Studies.

SUMÁRIO: Introdução. 1. O fenômeno jurídico na relação médico-paciente. 2. Natureza jurídica da relação médico-paciente. 3. A valoração da vontade do paciente como elemento estruturante da relação jurídica médico-paciente. 4 . O consentimento informado. 5. A crise do consentimento informado. 6. Requisitos para um consentimento informado. Considerações finais. Referências.

\section{INTRODUÇÃO}

Este artigo tenciona examinar o consentimento informado do paciente a partir da estrutura dos fatos jurídicos, conforme a disciplina da Teoria Geral do Direito Civil, considerando a manifestação de vontade do paciente requisito essencial à validade da prestação do serviço médico.

O interesse pela matéria relativa ao consentimento informado do paciente é próprio das recentes publicações do Código de Ética Médica no Brasil (2009) e do Código Deontológico em Portugal (2008), sendo o seu estudo ainda pouco explorado no Brasil, o que merece especial atenção nesse artigo, com o estudo baseado na doutrina desses dois países.

\footnotetext{
* Doutorado e Mestrado em Direito pela Universidade Federal de Pernambuco, Pós-Doutorado em Direito pela Faculdade de Direito da Universidade de Lisboa. Professor adjunto da Universidade Federal de Pernambuco. Juiz de Direito do Tribunal de Justiça do Estado de Pernambuco.
} 


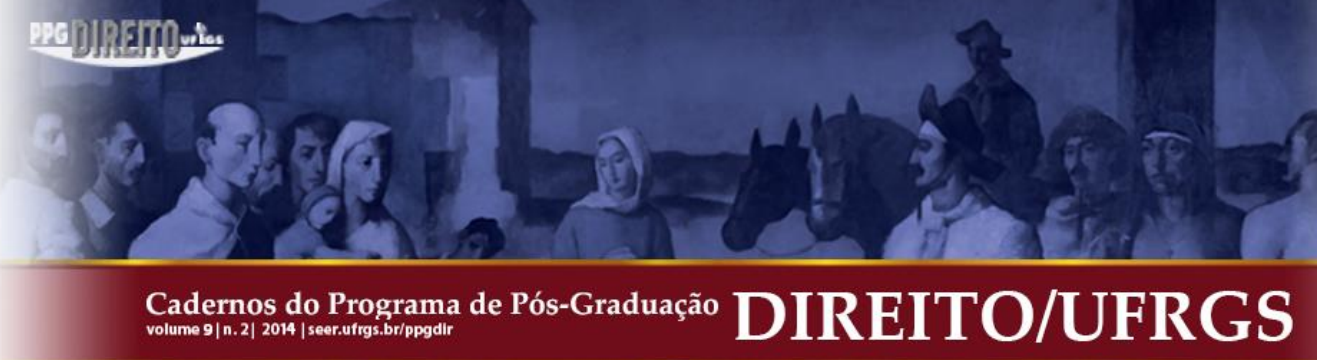

O comportamento do médico diante do paciente é tipificado por normas que determinam o seu agir e configuram suas responsabilidades, deveres, faculdades e poderes. ${ }^{2}$

Apesar de o tratamento médico sofrer a influência de fatores que envolvem a saúde do paciente, com diversas variáveis que podem alterar o tratamento, caso a caso, a expectativa social é a de que as ações e reações do médico sigam uma conduta previamente pensada, de modo que se estabeleça uma ordem, um procedimento expectado quanto a este comportamento.

Era assim desde Hipócrates ${ }^{3}$, o que hoje é representado pelo Código de Ética Médica no Brasil, pela Resolução CFM no. 1.931/2009 e em Portugal pelo Código Deontológico de 26 de setembro de 2008.

A estruturação de normas relativas ao comportamento do médico obriga que a análise da relação médico-paciente não seja simplesmente do ponto de vista da medicina, mas também do ponto de vista do direito e das demais disciplinas envolvidas.

Partindo do princípio de que as relações sociais são conflituosas, o direito surge tanto para regular tais relações impondo uma ordem, um comportamento, como para imputar responsabilidades àqueles que descumpram esta ordem pré-estabelecida, impondo sanções.

O estudo das relações entre médico e paciente deve ser realizado em seu sentido plural, uma vez que o estudo isolado da pessoa não produz relações jurídicas e não interessa ao direito.

Nesse sentido, os atos médicos, bem como todos os atos praticados na área da saúde envolvem uma relação entre pessoas, onde de um lado se encontra a pessoa do paciente em

\footnotetext{
${ }^{2}$ Ibid. p. 104.

3 “Eu juro, por Apolo, médico, por Esculápio, Higeia e Panaceia, e tomo por testemunhas todos os deuses e todas as deusas, cumprir, segundo meu poder e minha razão, a promessa que se segue: estimar, tanto quanto a meus pais, aquele que me ensinou esta arte; fazer vida comum e, se necessário for, com ele partilhar meus bens; ter seus filhos por meus próprios irmãos; ensinar-lhes esta arte, se eles tiverem necessidade de aprendê-la, sem remuneração e nem compromisso escrito; fazer participar dos preceitos, das lições e de todo o resto do ensino, meus filhos, os de meu mestre e os discípulos inscritos segundo os regulamentos da profissão, porém, só a estes. Aplicarei os regimes para o bem do doente segundo o meu poder e entendimento, nunca para causar dano ou mal a alguém. A ninguém darei por comprazer, nem remédio mortal nem um conselho que induza a perda. Do mesmo modo não darei a nenhuma mulher uma substância abortiva. Conservarei imaculada minha vida e minha arte. Não praticarei a talha, mesmo sobre um calculoso confirmado; deixarei essa operação aos práticos que disso cuidam. Em toda a casa, aí entrarei para o bem dos doentes, mantendo-me longe de todo o dano voluntário e de toda a sedução sobretudo longe dos prazeres do amor, com as mulheres ou com os homens livres ou escravizados. Àquilo que no exercício ou fora do exercício da profissão e no convívio da sociedade, eu tiver visto ou ouvido, que não seja preciso divulgar, eu conservarei inteiramente secreto. Se eu cumprir este juramento com fidelidade, que me seja dado gozar felizmente da vida e da minha profissão, honrado para sempre entre os homens; se eu dele me afastar ou infringir, o contrário aconteça.” JURAMENTO de Hipócrates. Disponível em: <http://www.cremesp.org.br/?siteAcao=Historia\&esc=3> Acesso em: 9 set. 2014.
} 


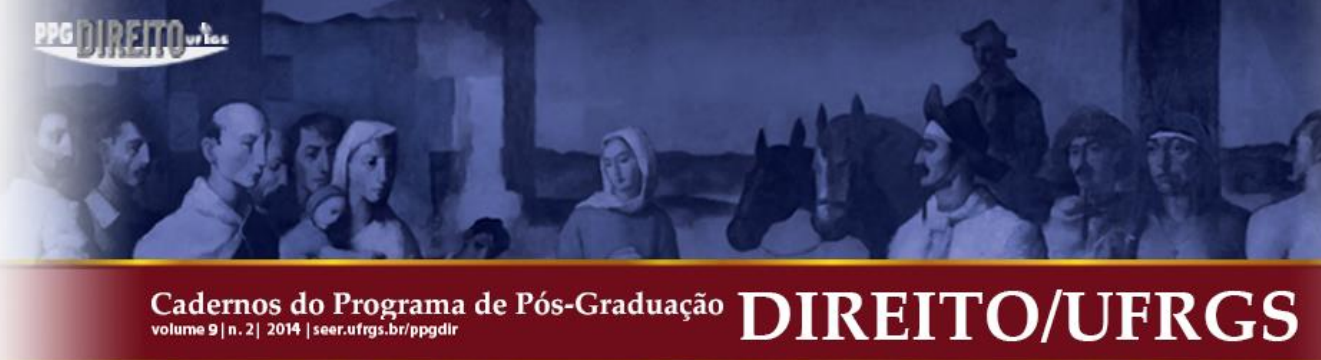

busca de tratamento médico, para prover seu bem estar físico, mental e social e do outro lado existe um profissional da saúde, em quem repousa todas as expectativas do paciente.

A dinâmica da relação médico-paciente não foge da apreciação do direito.

\section{NATUREZA JURÍDICA DA RELAÇÃO MÉDICO-PACIENTE}

A primeira questão que suscita o estudo da relação médico-paciente no âmbito do direito é saber qual a sua natureza jurídica. Ou seja, em qual modelo jurídico a relação médico-paciente se inclui.

Perguntar a natureza jurídica é saber em que categoria se enquadra o tipo estudado dentro dos diversos institutos jurídicos. Contudo, quando se fala da natureza jurídica da relação médico-paciente esta resposta não é assim tão fácil.

Inicialmente, o entendimento de parte da doutrina e dos tribunais brasileiros é o de reconhecer na relação médico-paciente a aplicação do Código de Defesa do Consumidor. Apesar da existência de decisões dos tribunais ${ }^{4}$ apontando a relação médico-paciente como uma relação de consumo, o que se pode verificar por estes mesmos julgados é que está regra não é geral, em face da diversidade dos serviços fornecidos pelo médico, que ora se encaixam como uma verdadeira relação de consumo, e que ora se apresentam como um contrato atípico que envolve uma relação personalíssima. ${ }^{5}$

Por sua vez, a doutrina majoritária portuguesa tem o entendimento de que a relação médico-paciente tem a natureza jurídica correspondente a de um contrato cível, regulado pelo Código Civil Português. ${ }^{6}$

\footnotetext{
${ }^{4}$ INDENIZACAO - TRATAMENTO MÉDICO - RELACÃO DE CONSUMO - INVERSÃO DO ONUS DA PROVA - NAO CABE AO PACIENTE DEMONSTRAR AUSÊNCIA DE QUALIDADE DO ATENDIMENTO. AO HOSPITAL E AO MÉDICO CABE A DEMONSTRAÇÃO DE QUE OS PROCEDIMENTOS ADOTADOS FORAM CORRETOS, E QUE O RESULTADO, MESMO ASSIM, NÃO PODE SER EVITADO. (Apelação Cível No 595157199, Sexta Câmara Cível, Tribunal de Justiça do RS, Relator: Ivan Leomar Bruxel, Julgado em 24/09/1996) (TJ-RS - AC: 595157199 RS, Relator: Ivan Leomar Bruxel, Data de Julgamento: 24/09/1996, Sexta Câmara Cível, Data de Publicação: Diário da Justiça do dia.

5 "Parece-nos claro que o paciente, ao contratar a execução de um serviço médico, desde uma simples consulta a um procedimento cirúrgico, seja ele considerado consumidor dos serviços oferecidos por este profissional". DANTAS, Eduardo. Direito Médico. Rio de Janeiro: GZ Editora, 2012, p. 163.

6 "Perante a Falta de Tipicidade legal, podemos ensaiar uma apresentação sumária do conteúdo desse contrato. Como ponto de partida, é seguro que se trata de um contrato civil (nunca é um acto de comércio), celebrado instituiu personae e é um contrato de consumo e, portanto, merecedor da aplicação das regras de proteção dos consumidores.” DIAS PEREIRA, André Gonçalo. O Consentimento Informado na Relação Médico-Paciente. Coimbra: Coimbra Editora, 2004, p. 36.
} 


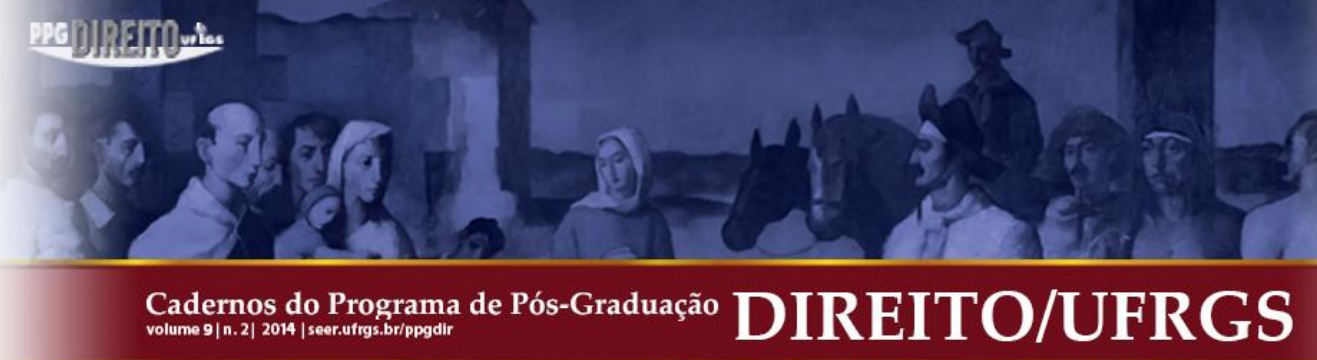

O Professor Pedro Romano Martinez, a respeito da doutrina portuguesa, acentua que a relação jurídica entre médico e paciente é de ordem obrigacional, podendo, caso a caso, ter origem em um contrato de prestação de serviços, em um negócio jurídico unilateral ou em uma atuação em gestão de negócios. ${ }^{7}$

Por outro lado, André Gonçalo Dias Pereira entende que existem situações em que não é possível enquadrar o tipo de relação médico-paciente como contratual, diante da inexistência própria de contrato, citando os casos de um incapaz, sem representantes legais, nos contratos nulos, como é o exemplo da prestação de serviços de aborto e nos atendimentos realizados nos hospitais públicos. ${ }^{8}$

Neste sentido, André Gonçalo Dias Pereira alimenta a controvérsia quanto as diferentes experiências do direito comparado e o direito português, acentuando que no Direito Português a relação paciente e hospital público seria da prestação de um serviço público, e não de um contrato. ${ }^{9}$

No Brasil, Paula Moura Francesconi de Lemos Pereira entende que a doutrina e a jurisprudência tem se inclinado para a determinação da natureza jurídica da relação entre o médico e o paciente como contratual, a partir da ideia de um negócio jurídico por meio do qual as partes estabelecem os efeitos que pretendem produzir a partir de suas declarações de vontade. Contudo, não exclui a hipótese de que em alguns casos e circunstâncias, a natureza jurídica da relação médico paciente pode não ser contratual, ai incluindo os serviços de saúde pública. $^{10}$

\footnotetext{
7 "Entre o paciente e o médico ou o hospital pode ter sido celebrado um contrato de prestação de serviços, sendo esta a situação jurídica mais comum. E, para efeito da indemnização por responsabilidade civil, é irrelevante o tipo e vínculo existente entre o hospital e o médico, pois aquele responde nos termos do art. $800^{\circ}$. $\mathrm{n}^{\circ} .1$ do CC. Tendo sido celebrado um contrato de prestação de serviços com o médico (hospital) aplicam-se as regras gerais dos contratos (art. $405^{\circ}$. do CC), o regime especial do contrato de mandato (art. $1156^{\circ}$. CC) e as regras de responsabilidade civil obrigacional (art. 798 ${ }^{\circ}$. e ss do CC). A relação obrigacional entre médico (ou o hospital) e o paciente pode também decorrer de um negócio jurídico unilateral ou de uma actuação em gestão de negócios." MARTINEZ, Pedro Romano. Responsabilidade Civil por Acto ou Omissão do Médico. In: DUARTE, Rui Pinto; FREITAS, José Lebre de; CRISTAS, Assunção; ALMEIDA, Marta Tavares de; NEVES, Vítor Pereira das (Orgs.). Estudos em Homenagem ao Professor Doutor Carlos Ferreira de Almeida. v. II. Coimbra: Almedina, 2011, p. 485.

${ }^{8}$ DIAS PEREIRA, op. cit., p. 40.

9 "Por outro lado, nem os médicos escolhem os doentes, nem os doentes normalmente escolhem os médicos. Os médicos trabalham em condições, com instrumentos e com pessoal auxiliar que não selecionaram. Por outro lado, o utente não está obrigado a qualquer contraprestação, à exceção do pagamento de uma taxa." Ibid. p. 45 e SS.

10 "É da essência da relação médico-paciente, portanto, o caráter contratual, mas em algumas circunstâncias o dever de assistência médica pode não decorrer de vínculo contratual direto entre o médico e o paciente. É o caso do médico servidor público, que atende em instituição obrigada a receber os segurados dos institutos de saúde
} 


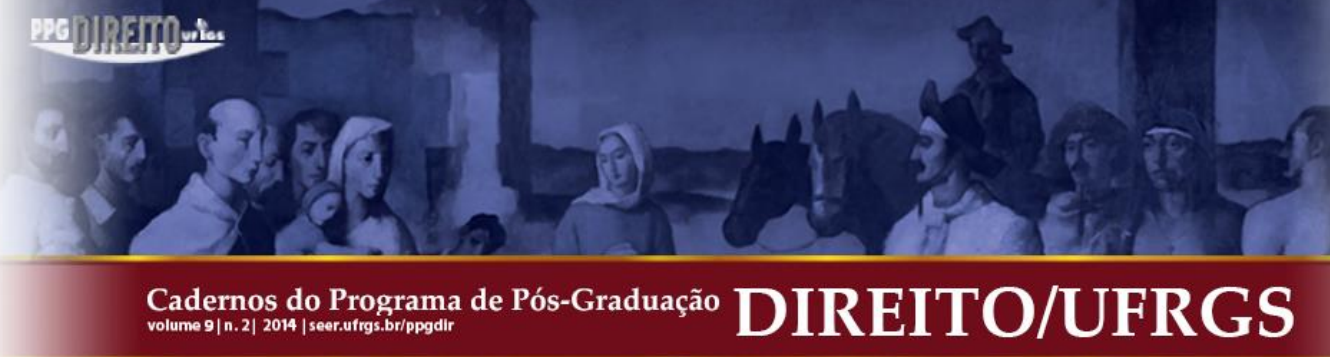

Ora, toda a discussão a respeito da natureza jurídica da relação médico-paciente envolve o interesse de investigar de que forma deve ser classificada a responsabilidade civil do médico. Trata-se de uma responsabilidade civil contratual, decorrente de uma relação de contrato, ou se uma responsabilidade civil extracontratual, decorrente da prática de um ato ilícito?

O estudo da natureza jurídica da relação médico-paciente é importante para o direito na medida em que é possível determinar em que tipo esta relação se encaixa, a fim de possibilitar a aplicação correta de seus preceitos, em especial a determinação do prazo prescricional, das obrigações decorrentes do conteúdo do contrato ou do serviço, bem como o ônus da prova.

Todavia, o que se pretende demostrar é que independentemente da classificação da relação jurídica médico-paciente como contratual ou extracontratual, é imposto ao médico deveres os quais, em todas essas situações, quer no tratamento em clínica particular quer no tratamento em hospital público o mesmo é obrigado a adotar.

Como o presente trabalho pretende investigar a valoração da vontade do paciente, levando-se em consideração a norma jurídica, nota-se que tal obrigação de informar não vai ser diferente na hipótese de um tratamento em uma clinica particular ou em um atendimento em hospital público. No caso do hospital público, como o elemento confiança é bem menor do que na relação entre um paciente e um médico por ele eleito, maior deve ser a atenção do médico em propiciar ao paciente as informações necessárias para um consentimento livre e esclarecido.

Assim em suas diferentes formas de se relacionar, o médico tem deveres gerais com o paciente que não serão fruto do tipo em que se encontra classificado, se contratual ou extracontratual, mas deveres oriundos do exercício próprio da profissão, a qual não irá diferenciar do tipo de médico, nem mesmo da natureza jurídica existente.

Desta forma, o contrato particular será simplesmente o instrumento da relação jurídica, sendo a pessoa o elemento mais importante a ser considerado, pois, o objeto da prestação de serviços médicos é a integridade física, a saúde e a vida da pessoa humana. ${ }^{11}$

pública, relação regulada pelo direito administrativo, ou do médico empregado, que trabalha em clínica, hospital privado, ou credenciado por plano de saúde.” LEMOS PEREIRA, Paula Moura Francesconi. Relação MédicoPaciente. Rio de Janeiro: Lumen Juris, 2011, p. 16.

11 “O contrato de serviços médicos é instrumental para a realização de determinados interesses existências, pois tem como objetivo a saúde, a integridade psicofísica, a dignidade do paciente. Por isso, sua análise não pode 


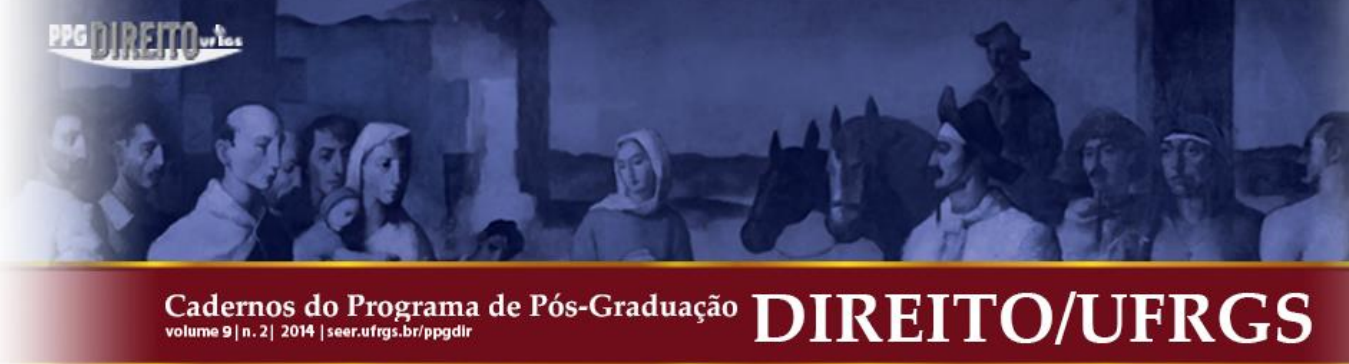

A importância da discussão da natureza da jurídica médico-paciente permite demonstrar que o médico não está isolado em sua relação com o paciente, detentor de poderes ilimitados da vida ou da morte, o médico é sujeito de obrigações, independente do contexto em que o mesmo esteja situado, e que o interesse maior tutelado é a dignidade da pessoa humana, em todas as suas formas de projeção.

Para além do enquadramento jurídico da relação médico-paciente, o procedimento e a atuação do médico obedecem a uma função social, com o Estado impondo normas que devem ser observadas como regras e limites ao exercício da profissão.

Para tanto, no Brasil existe o Código de Ética Médica, e em Portugal, o Código Deontológico da Ordem dos Médicos. Além das normas éticas constantes nos códigos médicos, estão os médicos ainda subordinados as normas de direito constitucional, de direito civil, de direito penal, entre outras, as quais regulam o exercício de sua profissão e tutelam interesses da pessoa humana. ${ }^{12}$

Diante disto, focando no tema do presente trabalho, tanto o Código de Ética Médica do Brasil, como o Código Deontológico da Ordem Médica de Portugal valorizaram a pessoa do paciente, e a manifestação de sua vontade durante o tratamento médico instituindo um capitulo especial regulando as relações entre o médico, o paciente e seus familiares.

\footnotetext{
Código Deontológico da Ordem Médica - Portugal

Artigo 45.

(Consentimento do doente)
}

1. Só é válido o consentimento do doente se este tiver capacidade de decidir livremente, se estiver na posse da informação relevante e se for dado na ausência de coacções físicas ou morais.

2. Sempre que possível, entre o esclarecimento e o consentimento deverá existir intervalo de tempo que permita ao doente reflectir e aconselhar-se.

3. O médico deve aceitar e pode sugerir que o doente procure outra opinião médica, particularmente se a decisão envolver grandes riscos ou graves consequências.

Código de Ética Médica - Brasil

estar adstrita aos aspectos patrimoniais, pois envolvem direitos da personalidade, o poder de disposição sobre situações existenciais, merecendo regime especial, por meio do qual se garantirá a igualdade substancial entre as partes contratantes, a preservação da dignidade da pessoa humana.” LEMOS PEREIRA, op. cit. p. 19.

12 "Independentemente da exacta identificação da fonte de onde deriva a legitimidade dessas normas, o resultado é, acompanhando Guilherme de Oliveira, que 'as normas deontológicas têm de se subordinar à legislação ordinária' e que a 'aplicação directa das normas deontológicas, pelos órgãos estatutariamente competentes, não deixa de exigir um controlo pelas instâncias judiciárias normais, na medida em que implica limitações de direitos civil, como o do exercício da profissão' Por outo lado, estas normas permitem 'preencher o conteúdo das normas que estabelecem os deveres do médico.” DIAS PEREIRA, op. cit., p. 102. 


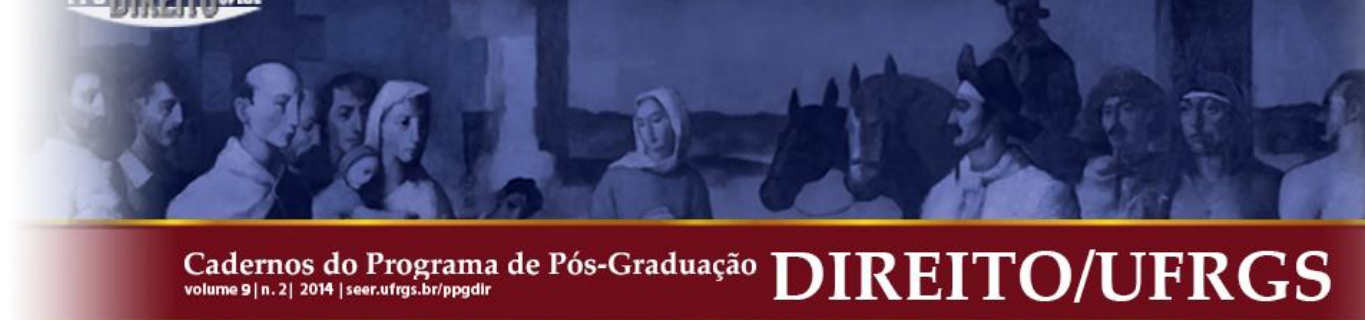

É vedado ao médico:

Art. 22. Deixar de obter consentimento do paciente ou de seu representante legal após esclarecê-lo sobre o procedimento a ser realizado, salvo em caso de risco iminente de morte.

O Estudo da vontade do paciente diante da dinâmica do consentimento informado, nas diversas situações e circunstâncias que envolvem o convívio social, é o objeto do presente trabalho, partindo da noção de autonomia da vontade e dos requisitos para a sua manifestação.

\section{A VAlORAÇÃo da VONTAde do PACIENTE COMO ELEMENTO ESTRUTURANTE DA RELAÇÃO JURÍDICA MÉDICO-PACIENTE}

A partir da ideia de que a natureza jurídica da relação médico-paciente é de um negócio jurídico, que pode se expressar pela forma contratual, por uma declaração unilateral de vontade ou pela gestão de negócios, a vontade da pessoa passa a ser o núcleo essencial deste negócio jurídico. ${ }^{13} 14$

A relação médico-paciente necessita da convergência da atuação da vontade das partes e do ordenamento jurídico para que o negócio jurídico seja válido e produza efeitos. ${ }^{15}$

Quando a vontade declarada pelo paciente se forma sobre uma motivação conforme com a realidade e com a liberdade, os efeitos jurídicos contidos na declaração serão válidos, pois, representam a valoração da sua autonomia. Contudo, pode o paciente por causas diversas expressar uma vontade que não corresponda a sua vontade real, provocando uma divergência que pode influenciar na validade do negócio jurídico envolvendo o médico e o paciente. $^{16}$

Por isso que, a compreensão da vontade do paciente é importante para a validade do tratamento médico. O paciente está tomado pela dor, pelo medo, pelo sofrimento, pelas várias circunstâncias que envolvem o tratamento médico, os quais podem ter influência na construção da sua vontade, tendo relevância e importância as informações que receba do médico e os seus valores existenciais para que o mesmo possa formar a sua convicção. ${ }^{17}$

\footnotetext{
13 "O conteúdo do negócio jurídico é a regulação que nele é posta em vigor, no âmbito da autonomia privada". VASCONCELOS, Pedro Pais. Teoria Geral do Direito Civil. 3. ed. Coimbra: Almedina, 2005, p. 417.

${ }^{14}$ MOTA PINTO, Carlos Alberto. Teoria Geral do Direito Civil. 4. ed. Coimbra: Editora Coimbra, 2012, p. 413.

${ }^{15}$ DIAS PEREIRA, op. cit., p. 480.

${ }^{16}$ MOTA PINTO, op. cit., p. 458.

17 "Os problemas decisivos para o efeito de determinar o conceito de declaração negocial - corresponde aos dados do sistema - são o da divergência entre a vontade e a declaração, o dos vícios da vontade, o da interpretação da declaração negocial, etc.” Ibid. p. 414.
} 


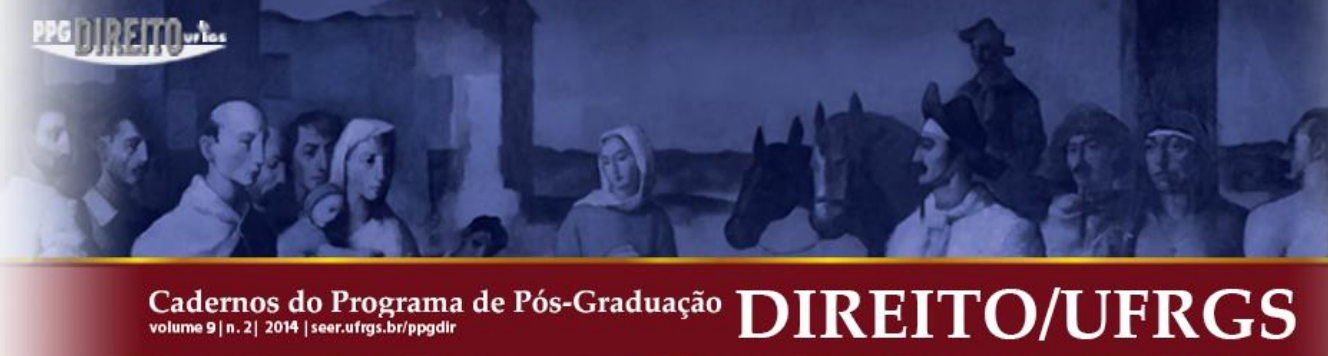

Assim, a relação médico-paciente não foge ao sistema da declaração negocial constitutivos do negócio jurídico, em que normalmente se destacam a declaração propriamente dita, como elemento externo e a vontade, como elemento interno. ${ }^{18}$

Dessa forma, a vontade interior como pressuposto do negócio jurídico deve ser exteriorizada por meio de sua declaração, de modo que o mundo exterior possa reconhecê-la.

A doutrina se preocupa com o estudo da vontade a partir dessas duas perspectivas, pois, é aspecto importante para a determinação da eficácia da declaração negocial na relação médico-paciente.

A construção da vontade dentro da perspectiva psíquica impõe ao paciente uma deliberação ${ }^{19}$, uma análise interior, de acordo com as informações que venha a receber do médico e as circunstâncias que envolvem o tratamento médico e dependerá para a sua validade e eficácia, que a declaração exteriorizada esteja em consonância com o intimo querer da pessoa, e que não se traduza, em face das circunstâncias, em uma falsa noção da realidade.

Por isso que não se deve afastar o fato de que o paciente para manifestar a sua vontade recebe, desde logo, os estímulos provocados pelos sintomas do mal que lhe atinge, as aflições, as dores, os sofrimentos, os quais integram as circunstâncias em que a sua vontade é expressa.

E mesmo ainda estando sujeito a esses estímulos exteriores, o paciente deve receber do médico as informações necessárias para compreender a doença e os sintomas que lhe afligem, bem como a forma ou formas de tratamento daquela doença, e o prognóstico de sucesso e cura.

Diante desses estímulos exteriores, do qual tem relevância as informações prestadas pelo médico, as circunstâncias do tratamento, as dores, o sofrimento, a cultura e os valores que a pessoa possua, o paciente fará sua deliberação, ponderando o que imagina ser melhor para si naquele momento, para ao final elaborar a sua vontade.

Elaborada a vontade, surge o terceiro momento, em que esta mesma vontade é manifestada para o exterior, sendo reconhecida pelo médico.

Ora, a validade e eficácia da declaração do paciente irá depender de diversos fatores, se o paciente tem a exata noção da realidade dos fatos, se foi devidamente informado, se é

\footnotetext{
${ }^{18}$ Ibid., p. 419.

19 "No campo puramente psíquico distinguem-se três momentos: o da solicitação, o da deliberação e o da ação. Primeiramente os centros cerebrais recebem o estimulo do meio exterior; em seguida, mais ou menos rapidamente, ponderam nas conveniências e resolvem como proceder; e finalmente reage a vontade à solicitação.” DIAS PEREIRA, op. cit. p. 481.
} 


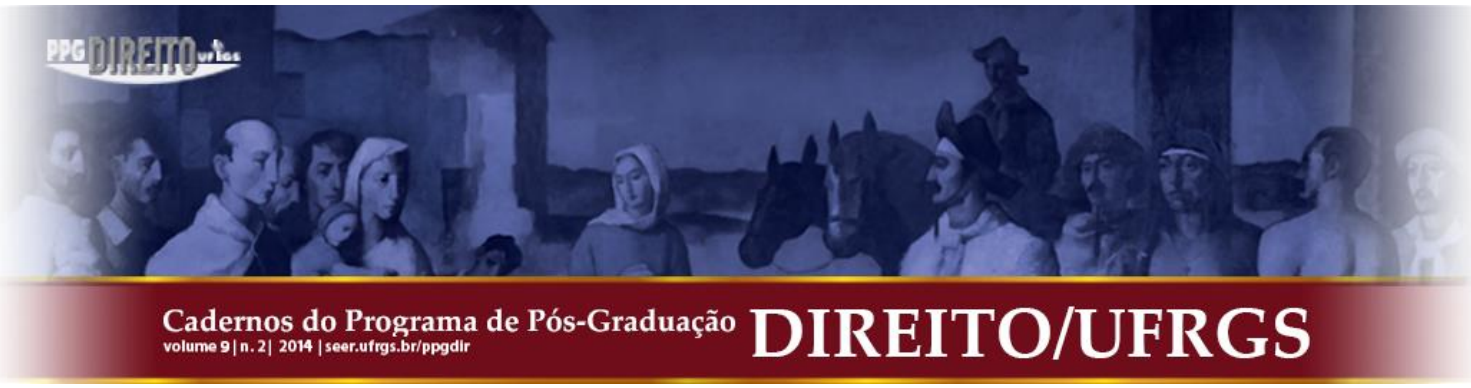

capaz, e se as dores não tenham viciado a sua vontade, estando a exteriorização de sua vontade em sintonia com a vontade interior.

Contudo, caso o médico não tenha prestado as informações necessárias, e ainda se o paciente não tiver capacidade de compreender os detalhes do tratamento, de modo que possa influenciar a sua capacidade para decidir, perdendo a exata noção da realidade, a manifestação de vontade exteriorizada por esta pessoa poderá não ser válida, nem eficaz. ${ }^{20}$

É certo que em um tratamento médico não se deve excluir a possibilidade de dor, de sofrimento, de medo, bem como a compreensão de que a liberdade e o discernimento não são absolutos, nem mesmo perfeitos e ilimitados, devendo a declaração ser analisada a partir do conceito médio de uma pessoa normal, diante dessas mesmas circunstâncias. ${ }^{21}$

Para a validade da manifestação da vontade deve-se acrescentar ao sentido declarado pelo paciente, todas as circunstâncias que envolvem o seu tratamento, como forma de auxiliar a correta compreensão de sua vontade e como elemento essencial para a busca do seu desejo interior.

A busca pela vontade interior de modo a tentar chegar a uma vontade mais próxima da realidade interna, depende das circunstâncias que determinaram a manifestação da vontade do paciente para a realização do tratamento, pois, passa a ter importância os seus valores e a sua cultura, o seu estado de hipossuficiente em relação ao médico, entre outras circunstâncias possíveis.

É evidente que a estrutura do negócio jurídico na relação médico-paciente difere da estrutura de uma relação obrigacional patrimonialista, haja vista que o objeto especifico da obrigação envolve interesses da personalidade como o corpo, a saúde e a vida do paciente, valores estes que superam os bens patrimoniais, determinando uma função social especifica para os contratos de saúde, com regras próprias para a relação médico-paciente.

\footnotetext{
20 “O negócio jurídico apresenta-se como uma manifestação da autonomia privada; nessa medida, ele deve corresponder à vontade autónoma das pessoas ou mais não será do que um simulacro de autonomia: o Direito sendo, como é, uma Ciência - não pode assentar em equívocos ou em ficções.” CORDEIRO, Antônio Menezes. Tratado de Direito Civil Português. Parte Geral. t. I. Coimbra: Almedina, 2005, p. 542.

21 “O negócio jurídico, como acto de autonomia privada e como acção que gera e põe em vigor uma regulamentação interprivada, com o seu carácter criador de direito, supõe e exige de parte dos seus autores liberdade e discernimento. Não existem, porém, liberdade e discernimento que sejam absolutos, que sejam perfeitos e ilimitados. A autonomia privada contenta-se com a liberdade e o discernimento normais, isto é, que são próprios das pessoas normais, das pessoas comuns. Para celebrar um negócio jurídico não é, por isso, necessário estar completamente livre de constrangimentos. A própria vida em sociedade, com as suas circunstâncias, o contacto social e o contacto com a natureza, constrangem e limitam a liberdade das pessoas." VASCONCELOS, Pedro Pais. Teoria Geral do Direito Civil. 3. ed. Coimbra: Almedina, 2005, p. 491.
} 


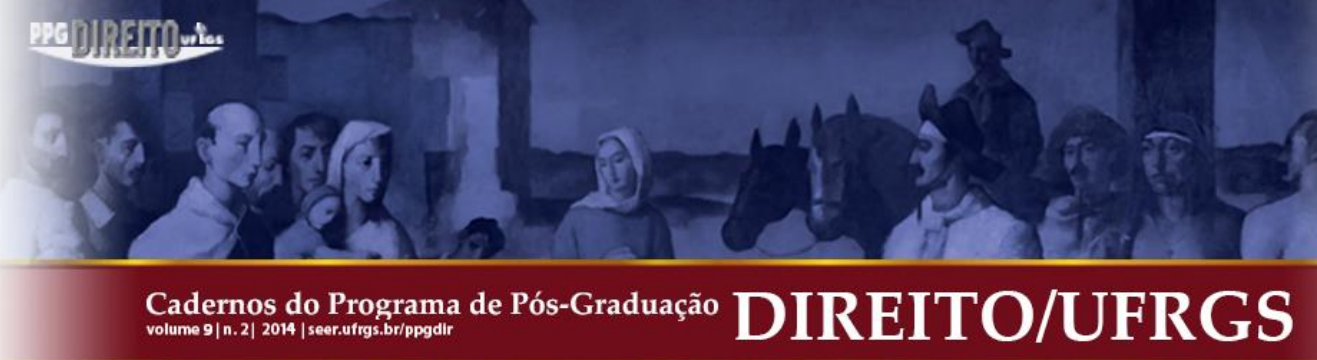

Assim, a valoração da vontade do paciente integra uma lógica de respeito ao desenvolvimento de sua autonomia pessoal, seu corpo, sua saúde, sua vida, valores estes fundados no principio da dignidade da pessoa humana, que alteram a função do negócio jurídico médico-paciente em relação ao negócio jurídico patrimonial. ${ }^{22} 23$

Desta forma, a busca pela vontade interior do paciente deve ser uma obstinação do médico, pois, as suas expectativas em relação ao seu bem estar, envolve, entre outros aspectos, os seus valores, sua cultura, os seus sentimentos, de modo que o respeito a vontade do paciente interessa a garantia do livre desenvolvimento da personalidade ${ }^{24}$ deste mesmo paciente.

\section{O CONSENTIMENTO INFORMADO}

Quando o Código de Ética médica determina a necessidade de se obter o consentimento informado, estabelece que todo paciente tem o direito de decidir livremente, depois de devidamente informado, entre as diversas opções clinicas que pode se submeter, podendo, inclusive, optar pela recusa ao tratamento. ${ }^{25}$

O consentimento informado deve ser obtido em todo o tipo de intervenção médica, sempre de forma proporcional a capacidade de compreensão do paciente, por isso a importância da informação a ser prestada pelo médico, de modo que o paciente possa compreender e medir a dimensão do tratamento, a sua necessidade e utilidade, para que ao final tenha condições de manifestar a sua vontade. ${ }^{26} 27$

22 "O negócio jurídico que se mantenha sem vontade real não é já um verdadeiro negócio mas, antes, uma manifestação de confiança tutelada; tal tutela exige, desde logo, toda uma série de dispositivos legais que a facultem e que não se confundem com a autonomia privada." CORDEIRO, op. cit. p. 542.

23 "A autonomia privada, no exercício do direito de personalidade tem dois aspectos principais: o da iniciativa na defesa da personalidade e a da auto-vinculação à sua limitação ou compressão. No primeiro dos referidos aspectos, o titular é livre de exercer o seu direito ou de se abster de o fazer. Num caso de ofensa corporal, a vítima pode abster-se de se defender e até de recorrer aos meios públicos de defesa (policia, tribunais), pode, por exemplo, 'dar a outra face'. É livre de escolher a sua atitude perante a ofensa. Esta liberdade é reveladora da autonomia do titular que pode decidir, só por si e livremente, sobre o exercício do direito, sem estar vinculado heteronomamente. Num outro exemplo, o doente pode não querer ser tratado." VASCONCELOS, Pedro Pais. Teoria Geral do Direito Civil. 3. ed. Coimbra: Almedina, 2005, p. 153.

${ }^{24}$ VASCONCELOS, op. cit., p. 74.

${ }^{25}$ RIESTRA, Sergio Gallego. El Derecho del Paciente a la Autonomia Personal y las Instruciones Previas: uma Nueva Realidad Legal. Navarra: Aranzadi, 2009, p. 112.

26 “Alejándose del término 'información completa', se refería a ella como información adecuada sobre la finalidad y naturaliza de la intervención y en su Informe Explicativo se indica que debe ser suficientemente clara y formulada de una manera adecuada a la persona que va a someterse a la intervención, de forma que el paciente este en condiciones, gracias al empleo de términos que pueda entender, de sopesar la necesidad o utilidad e del 


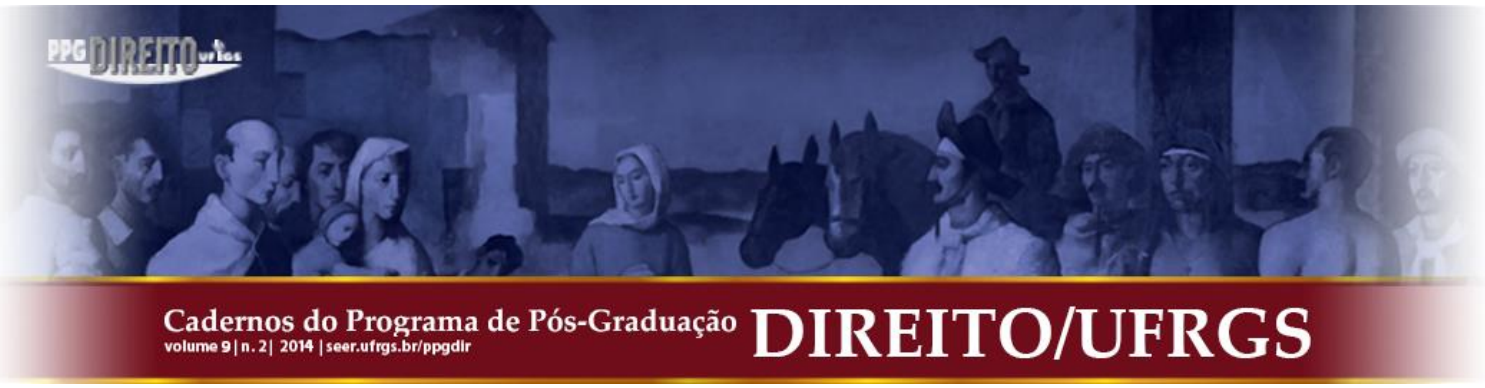

O consentimento informado é assim a expressão da autonomia da vontade do paciente, seguro de seus propósitos, diante dos esclarecimentos apresentados pelo médico. ${ }^{28}$

O consentimento informado envolve dois momentos especiais:

a) o primeiro momento em que a informação é concedida com clareza suficiente para que possibilite a correta compreensão. ${ }^{29}$

b) e o segundo momento onde em razão da reflexão do conhecimento adquirido há a manifestação livre da vontade.

A razão do consentimento informado será assim, a de compensar o desnível de informação existente entre o médico e o paciente, desempenhando relevo fundamental à existência de uma especial necessidade de proteção do paciente, resultante do mesmo não ser capaz de divisar seus próprios interesses, impossibilitado de discutir os termos gerais do tratamento médico, sem uma correta informação.

Ora, tratando-se de uma intervenção médica, a necessidade de um consentimento livre e inequívoco, decorre do princípio da inviolabilidade do corpo ${ }^{30}$ e do princípio da autonomia da vontade, como a liberdade que o ser humano tem para conduzir a sua vida privada.

Segundo as lições de Marco Segre e Claudio Cohen, a compreensão de autonomia na relação médico-paciente, entende que ambos devem ser competentes e, portanto, livres para poderem avaliar as opções possíveis, permitindo uma escolha consciente e consequente. ${ }^{31}$

fin y los métodos de la intervención frente a los riesgos, cargas o dolor que ésta supone.” RIESTRA, op. cit., p. 112.

27 “O esclarecimento não pode ter um caráter estritamente técnico em torno de detalhes de uma enfermidade ou de uma conduta. A linguagem própria dos técnicos deve ser decodificada para o leigo, se não ele tende a interpretações duvidosas e temerárias. É correto dizer ao doente não só os resultados normais, senão ainda os riscos que determinada intervenção pode trazer, sem, contudo, a minuciosidade dos detalhes mais excepcionais. É certo que o prognóstico mais grave pode ser perfeitamente analisado e omitido em cada caso, embora não o seja à família.” FRANÇA, Genival Veloso. Direito Médico. Rio de Janeiro: Forense, 2013, p.21.

28 "Num segundo grupo, a culpa in contrahendo prevê deveres de esclarecimento a cargo das partes em negociações. A conclusão de um contrato na base de falsas indicações, de informação deficiente ou, até, de ameaças ilícitas, independentemente da aplicabilidade do regime próprio dos vícios na formação da vontade, implica o dever de indemnizar, por culpa na formação dos contratos. Este dever de esclarecimento tem intensidade particular quando um contratante surja, perante outro, como carecido de proteção especial." CORDEIRO, Antônio Menezes. Tratado de Direito Civil Português. Parte Geral. t. I. Coimbra: Almedina, 2005, p. 549.

29 "Os deveres acessórios de esclarecimento obrigam as partes a, na vigência do contrato que as une, informarem-se mutuamente de todos os aspectos atinentes ao vínculo, de ocorrências que, com ele, tenham certa relação e, ainda, de todos os efeitos que, da execução contratual, possam advir. O campo mais produtivo no domínio do dever de esclarecimento é o dos contratos de prestação de serviços, utilizáveis como exemplares." CORDEIRO, op. cit., p. 605.

${ }^{30}$ LEITE, op. cit., p. 31.

31 "Para que uma ação possa considerar-se autônoma, poderíamos exigir uma substancial satisfação dessas condições, um completo ou quase completo entendimento da situação e/ou uma completa ausência de influência. 


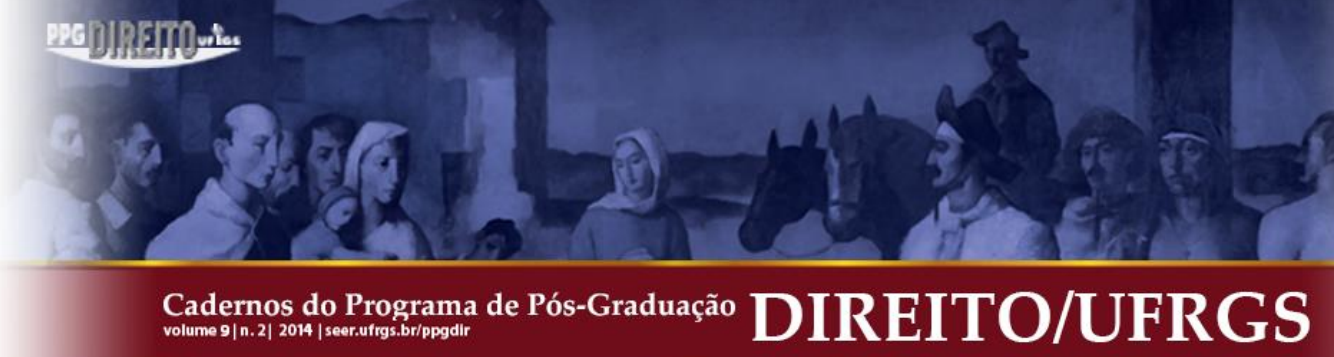

Nesse sentido, a autonomia é um conceito que está ligado à escolha reflexiva individual.

Assim, o respeito à autonomia da vontade pode ser interpretado dentro de uma larga extensão, não podendo ser aplicado às pessoas que não estejam em condições de agir de maneira suficientemente autônoma. As pessoas incapazes, ignorantes, débeis, crianças, dependentes de drogas, não estão em condições de manifestar de forma livre e refletida a sua vontade.

Inicialmente, antes que o paciente tenha condições de decidir se um tratamento médico lhe é aceitável, segundo seu próprio plano de vida, ou projeto familiar, deve o mesmo ser informado das possibilidades médicas de intervenção, suas recomendações, além da visão do próprio médico e como as recomendações afetam os valores do seu paciente.

Segundo o Relatório da Entidade Reguladora de Saúde de Portugal a respeito de consentimento informado, publicado em maio de 2009, o consentimento teria os seguintes pressupostos: ${ }^{32}$

1. O consentimento informado para tratamentos médicos, participação de doentes em ensaios clínicos e projectos de investigação e participação de doentes em acções de formação pré-graduada e pós-graduada é um requisito ético e jurídico fundamental.

2. O consentimento informado é uma manifestação de respeito pelo doente enquanto ser humano. Reflecte, em particular, o direito moral do doente à integridade corporal e à participação nas decisões conducentes à manutenção da sua saúde.

3. O consentimento informado assegura não só a protecção do doente contra a sujeição a tratamentos não desejados, como uma participação activa na definição dos cuidados de saúde a que é sujeito.

4. Para um consentimento informado de qualidade, a comunicação eficaz é fundamental e as instituições devem instaurar mecanismos que a assegurem, não só entre o médico e o doente como também entre os diversos profissionais.

5. O consentimento informado deve ser encarado como um processo contínuo e participado, e não como uma mera assinatura de formulários.

6. O consentimento informado não pode, em circunstância alguma, conflituar com os princípios éticos que regulam a prática médica, e não constitui justificação para que os clínicos deles abdiquem.

7. As situações em que o consentimento não é possível devem estar tipificadas e devem ser assumidas pelas instituições como situações de excepção, devidamente justificadas.

8. Os princípios éticos do consentimento informado não podem, em qualquer circunstância, sobrepor-se às leis gerais do País.

Levando estas questões a um último grau, e colocando-as num mundo prático, observaremos o quão serão as ações pessoais autônomas, até mesmo nunca o sendo. O objeto realista é, apenas, que uma decisão consequente seja substancialmente autônoma." SEGRE, Marco; COHEN, Claudio. Bioética. São Paulo: Editora da Universidade de São Paulo, 1995, p. 88.

32 ENTIDADE Reguladora de Saúde - Consentimento informado - Relatório final. Disponível em: <https://www.ers.pt/uploads/writer_file/document/73/Estudo-CI.pdf>. Acesso em: 9 set. 2014. 


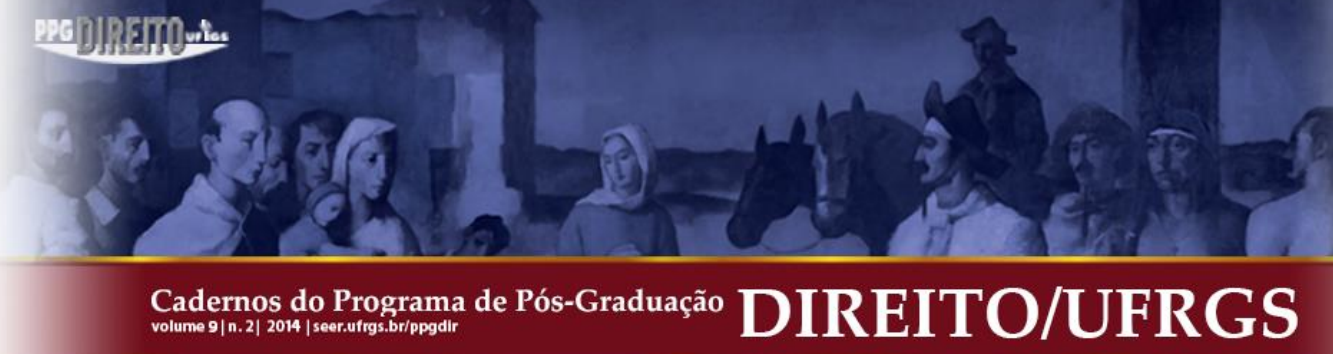

Assim, o consentimento informado além de um requisito ético fundamental, o qual deve o médico respeitar, é um direito do paciente, em face do seu direito ao livre desenvolvimento da personalidade, em defesa de seus interesses próprios na proteção da vida e da integridade física.

\section{A CRISE DO CONSENTIMENTO INFORMADO}

Do estudo do consentimento informado é possível dizer que ele já nasceu em crise. Ou até mesmo, dentro de outra forma de pensar, apesar dos fundamentos éticos do consentimento informado ser antigo, o seu conceito ainda é bastante jovem e impreciso. ${ }^{33}$

O ideal ético do consentimento informado, segundo Lewis Vaughn, tem tido bastante dificuldade para ser definido com precisão e aplicado aos casos concretos da vida real, bem como para incorporar e dar efetividade as leis e as políticas públicas, existindo ainda muitas dúvidas entre os profissionais da saúde e dos pacientes quanto a sua verdadeira importância e influência ${ }^{34}$.

A concepção paternalista do médico em relação ao paciente e o seu adequado tratamento faz com que a vontade do médico prevaleça, por se sentir superior e especial. Superior em razão de deter o conhecimento científico relativo ao tratamento médico e especial por estar muitas vezes diante de uma complexidade técnica, que regula o próprio tratamento médico, o qual diminui os espaços para a livre manifestação da vontade.

Segundo David Rodrigues-Arias, os hábitos se revelam mais difíceis de serem mudados do que as próprias leis, pelo menos isto pode ser dito em relação ao consentimento informado, vez que atualmente somente uma minoria dos pacientes exerce o seu direito de decidir quanto aos limites do tratamento. ${ }^{35}$

Muitos médicos seguem um procedimento padrão para determinados tratamentos, como forma de se precaverem de futuras ações de responsabilidade civil, de acordo com

\footnotetext{
${ }^{33}$ VAUGHN, Lewis. Bioethics. Principles, Issues, and Cases. New York: Oxford University Press, 2013, p. 181.

${ }^{34}$ Ibid., p. 180.

${ }^{35}$ RODRIGUEZ-ARIAS, David. Una Muerte Razonable. Bilbao: Desclée de Brouwe, 2005, p. 38
} 


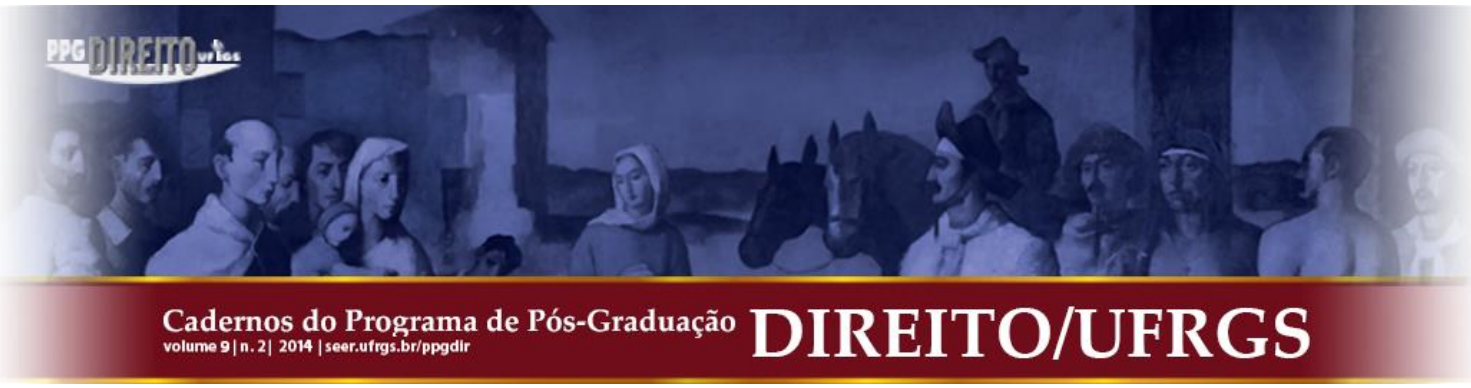

diretrizes que se tornam verdadeiros regulamentos, limitando tanto a atuação do médico, como a liberdade do paciente. ${ }^{36}$

Por outro lado, o próprio paciente não tem a correta percepção do melhor tratamento ao qual deve ser submetido, mesmo depois de devidamente informado, por lhe faltar a devida compreensão dos fatos. Somam-se a isto, aqueles relacionados às pessoas maiores, mas, sem capacidade de consentir, e aqueles relacionados às pessoas incapazes, em que o consentimento deve ser obtido por meio de seu representante legal. Sem falar nas hipóteses de conflito entre a vontade do paciente e o entendimento do médico.

O consentimento informado é justificado na bioética pelo principio da autonomia e da beneficência,

Contudo, por muito tempo o que prevaleceu foi a concepção paternalista da relação médico paciente, baseada no próprio juramento de Hipócrates. ${ }^{37} 38$

A teoria paternalista, desde a sua fonte histórica, considerava o paciente um sujeito incapaz porque a enfermidade perturbava a sua sanidade mental, influenciando assim, em não poder decidir o seu destino. ${ }^{39}$

O paternalismo é conceituado como uma forma de impor as crenças do médico ao paciente, sem o seu consentimento, ou até mesmo contra a sua vontade, mas com a intenção de prover o próprio beneficio do paciente.

A expressão paternalista é utilizada com frequência para se referir à relação entre pais e filhos, no caso o tratamento que o médico proporciona aos seus pacientes é comparado ao tratamento fornecido pelo pai ao filho, em que baseada na autoridade paternal se permite tomar decisões em nome dos filhos, anulando os seus desejos e decisões. ${ }^{40}$

\footnotetext{
${ }^{36}$ DIAS PEREIRA, op. cit., p. 76.

37 "Note-se que, nos textos atribuídos a Hipócrates, recomendava-se que o médico escondesse tudo o que pudesse do doente, desviando mesmo a atenção dele daquilo que lhe estava a fazer e omitindo o prognóstico que lhe reservava ... Mas há quem afirme que o exercício da medicina nunca foi tão autoritário como estas passagens fazem crer senão, porventura, durante a Idade Média, quando a prática clínica esteve confiada aos monges, habituados a relações organizadas de uma forma hierárquica severa, e ao dogma.” OLIVEIRA, Guilherme. Estrutura Jurídica do Acto Médico, Consentimento Informado e Responsabilidade Médica, Temas de Direito da Medicina. Coimbra: Editora Coimbra, 2005, p. 60.

38 "Haz todo esto con calma y orden, ocultando al enfermo, durante tu actuación, la mayoría de las cosas. Dale las órdenes oportunas con amabilidad y dulzura, y distrae su atención; repréndele a veces estricta y severamente, pero otras, anímale con solicitud y habilidad, sin mostrarle nada de lo que va a pasar ni de su estado actual; pues muchos acuden a otros médicos por causa de esa declaración, antes mencionada, del pronóstico sobre su presente y futuro". RIESTRA, op. cit., p. 54.

${ }^{39}$ Ibid., p. 11.

${ }^{40}$ Ibid., p. 57.
} 


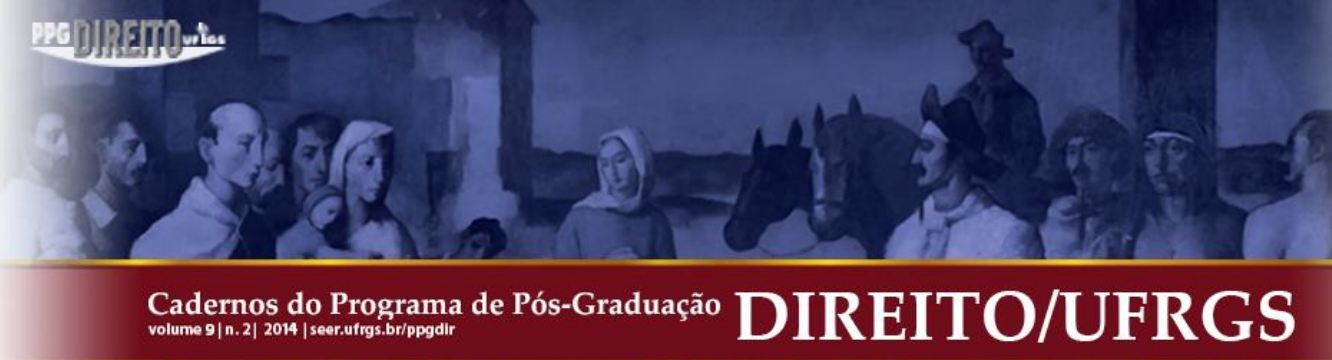

Podendo-se então defini-la, segundo Sergio Riestra, como a limitação intencionada da autonomia de uma pessoa por parte de outra, quando a pessoa que limita a autonomia apela exclusivamente para motivos de beneficência em favor da pessoa que tem a sua autonomia limitada. ${ }^{41}$

Por outro lado, o Consentimento informado se baseia no princípio da autonomia, em que se devem respeitar as eleições e opiniões das pessoas quanto ao seu tratamento de saúde.

Sergio Riestra analisando os princípios que presidem as relações entre médico e paciente declara que somente existe um único principio nesta relação, que é o princípio da autonomia, os demais a ele aderem e somente são convocados em caso de impossibilidade de se expressar a autonomia da pessoa. ${ }^{42}$

A autonomia determina que se deva respeitar a capacidade das pessoas de se autorregularem, bem como de serem respeitadas em suas escolhas, mesmo que suas determinações entrem em conflito com as advertências de seus médicos, contrapondo-se a concepção paternalista ${ }^{43}$.

O princípio da autonomia supõe, assim, a necessidade de se respeitar a liberdade e autodeterminação do paciente, e é considerada a própria fonte dos direitos do paciente, como uma forma de limitar os poderes dos médicos e de proteger o paciente contra os tratamentos não autorizados ${ }^{44}$.

Contudo, muitas vezes é difícil determinar os elementos que constituem uma ação autônoma do paciente, principalmente quando o mesmo está em uma situação de dor e de sofrimento.

Alguns doutrinadores elegem como requisito da autonomia a ausência de um controle interno, entendendo-se como a ausência de uma coação interna que possa controlar a vontade do paciente, fazendo com que o mesmo tome uma decisão diferente de seus próprios valores. Elegem como coação interna a dor, o sofrimento, o medo, a depressão e as enfermidades mentais. Por outro lado, Sergio Riestra entende que a ausência de coação interna deve ser

\footnotetext{
41 Ibid.

42 'No estamos de acuerdo con que los principios éticos sean principios 'prima facie', sino que han de ser jerarquizados por sí mismos y no como consecuencia de que entren en colisión. Ha de haber un principio preferente y tan sólo en determinados supuestos serán de aplicación el resto. Dentro de nuestra propuesta de jerarquización el lugar preeminente lo ocupa el principio de autonomía, siendo realmente el único principio 'prima facie' y tan sólo excepcionalmente entrarán en juego los demás teniendo entonces que hacerse la correspondiente ponderación atendiendo a las circunstancias concretas de cada caso.” Ibid., p. 12.

${ }^{43}$ VAUGHN, op. cit. p. 180.

${ }^{44}$ RIESTRA, op. cit. p. 66.
} 


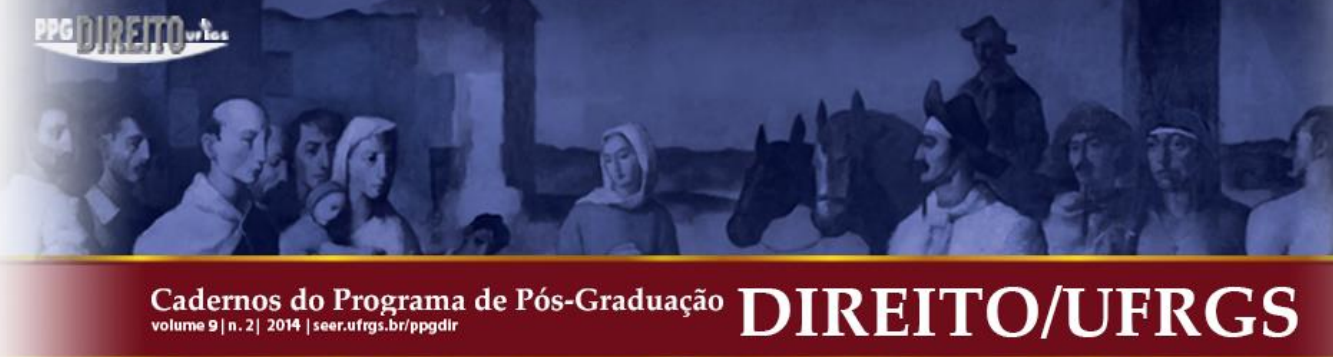

entendida como elemento do conhecimento, compreensão e intencionalidade, esclarecendo que muitas vezes a pessoa coagida por alguma força interna prática uma ação involuntária, sem qualquer intenção, a qual compreende e tem conhecimento, mas que não tem controle. ${ }^{45}$

A verdade é que a autonomia do paciente pode ser influenciada por problemas relacionados à dor, ao sofrimento, a depressão, entre outros, não sendo isto um caso simples de se revolver, pois, a pessoa pode inclusive decidir de forma contrária a sua vontade e seus valores. $^{46}$

Por sua vez, o agir segundo o princípio da beneficência corresponde à atuação do médico, quando o paciente não pode decidir por si mesmo. Neste caso, o agir do médico deve ser para beneficiar o paciente, para lhe prover o seu bem estar, quando o mesmo não possa exercer a sua autonomia.

Diversas controvérsias surgem quando da aplicação desses princípios no dia a dia, em relação aos casos em concreto. O que renova a expressão que o consentimento informado já nasceu em crise, onde até mesmo o reconhecimento da autodeterminação não garante ao paciente o melhor tratamento, quando a questão econômica interfere diretamente no acesso aos meios sanitários necessários ao paciente, em face do próprio sistema público de saúde, ou até mesmo pela limitação a certas técnicas e processos de diagnóstico. ${ }^{47}$

Enfim, apesar da teoria determinar os elementos necessários para a obtenção do consentimento informado, e o regulamento médico determinar a obrigatoriedade da obtenção do consentimento informado, a vida real em seus casos concretos está demonstrando a existência de diversas controvérsias envolvendo a autonomia do paciente e o dever de beneficência do médico.

E ai, a ideia de consentimento informado é bem maior do que simplesmente permitir um tratamento, e muito mais do que a autorização do paciente dada ao médico, conforme o desejo e expectativa do médico. O consentimento informado é um procedimento, onde a

\footnotetext{
${ }^{45}$ Ibid. p. 69.

46 "A 64-year-old woman with MS is hospitalized. The team feels she may need to be placed on a feeding tube soon to assure adequate nourishment. They ask the patient about this in the morning and she agrees. However, in the evening (before the tube has been placed), the patient becomes disoriented and seems confused about her decision to have the feeding tube placed. She tells the team she doesn't want it in. They revisit the question in the morning, when the patient is again lucid. Unable to recall her state of mind from the previous evening, the patient again agrees to the procedure.

Is this patient competent to decide? Which preference should be honored?" ETHICS in Medicine. University of Washington School of Medicine. Informed Consent: Case 1. Disponível em: <http://depts.washington.edu/bioethx/topics/consntc1.html>. Acesso em: 9 set. 2014.

${ }^{47}$ DIAS PEREIRA, op. cit., p. 76.
} 


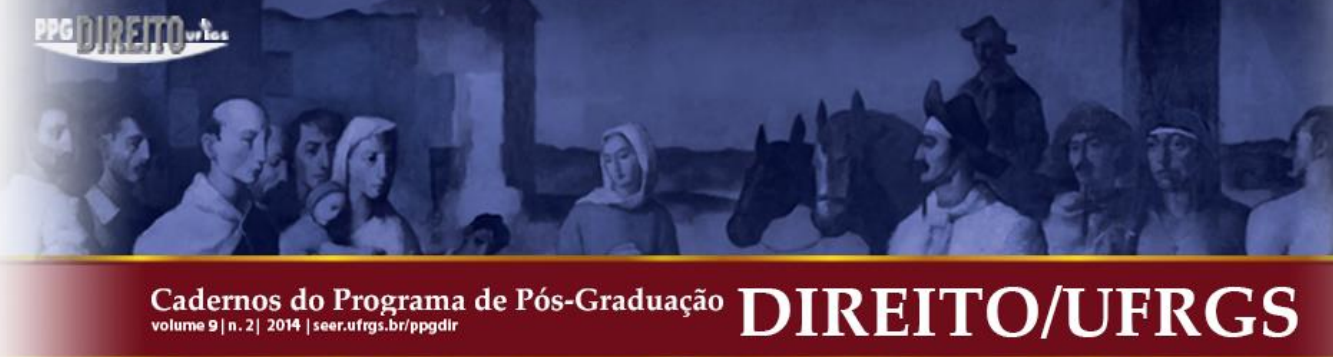

pessoa não diz simplesmente "sim", mas de forma autônoma e esclarecida decide e assume a responsabilidade por sua decisão. Inclusive, o preenchimento de um formulário padrão não representa em regra, um consentimento livre, aprofundado e esclarecido ${ }^{48}$.

\section{REQUISITOS PARA UM CONSENTIMENTO INFORMADO}

A doutrina tem estudado os requisitos para o consentimento informado, os quais acreditam que compõem o seu próprio objeto.

Então o Consentimento informado válido necessitaria dos seguintes componentes: ${ }^{49}$

a) Capacidade do paciente para decidir;

b) A devida divulgação da informação esclarecida;

c) A devida compreensão da informação;

d) Uma decisão voluntária quanto ao tratamento;

e) O consentimento dirigido ao tratamento.

$\mathrm{Na}$ teoria parece simples a compreensão dos requisitos necessários para o consentimento informado, contudo, diante dos fatos que envolvem os casos reais, encontra-se bastante dificuldade para verificar sua adequada aplicação, principalmente diante da análise da capacidade para decidir, bem como quanto à devida divulgação da informação esclarecida.

A capacidade do paciente está ligada tanto à sua capacidade de fato dentro da Teoria Geral do Direito Civil ${ }^{50}$, como faculdade que tem a pessoa de por si só tomar as decisões necessárias em sua vida, como sujeito de direito e obrigações, quanto e ainda mais, está ligada verdadeiramente a sua capacidade para tomar decisões acerca das intervenções médicas.

Neste sentido, as condições pessoais do paciente irão influenciar no modo que estas informações serão prestadas, bem como na capacidade do paciente decidir.

Podem ocorrer casos em que a pessoa pode ser considerada capaz para os atos da vida civil, mas que não tenha capacidade para expressar a sua vontade, diante de questões médicas,

\footnotetext{
${ }^{48}$ VAUGHN, op. cit., p. 184.

${ }^{49}$ Ibid. p. 181.

50 “A esta aptidão oriunda da personalidade, para adquirir os direitos na vida civil, dá-se o nome de capacidade de direito, e se distingue da capacidade de fato, que é a aptidão para utilizá-los e exercê-los por si mesmo." PEREIRA, Caio Mario da Silva. Instituições de Direito Civil. v. I. 22. ed. Rio de Janeiro: Forense, 2007, p. 263.
} 


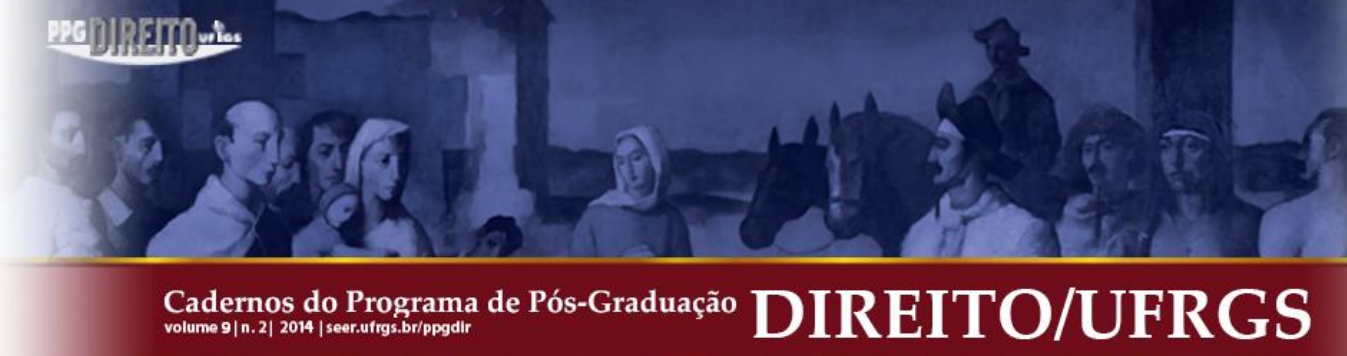

ou porque se encontra diante de uma dor insuportável, ou possua um medo relevante que o impeça momentaneamente de expressar a sua vontade.

Por outro lado, pode uma pessoa ser declarada incapaz para a prática de atos financeiros, por insolvência civil, e apesar disto ter condições de se manifestar quando a sua saúde e seu tratamento.

Há ainda casos em que a pessoa declina de sua competência para decidir quanto ao melhor tratamento, e atribui está responsabilidade ao médico, abrindo mão da sua autonomia e do direito de escolha, passando a ser considerado incapaz de decidir, em face da sua renuncia. ${ }^{51}$

A analise desta capacidade é realizada pelo próprio médico.

Aquelas pessoas consideradas incapazes serão substituídas por um procurador de cuidados de saúde ou por um ente familiar próximo. Os quais devem ser devidamente informados quanto aos tratamentos que devem ser praticados, seus riscos e benefícios.

Mas aqui há um detalhe importante: a manifestação de vontade do procurador deve ser sempre no sentido de prover o melhor para o paciente, e na medida do possível deve tentar se adequar a vontade do paciente declarada no momento em que possuía capacidade. ${ }^{52}$

Assim, a análise da capacidade do paciente para decidir quanto ao melhor tratamento irá depender da análise do médico, caso a caso, o que envolve pacientes com capacidade, pacientes sem capacidade, podendo ainda verificar dentre aqueles que não possuem capacidade, alguns que realizaram manifestação de vontade adiantada, e outros que não se conhece a sua vontade por nunca terem se manifestado.

Além do mais, quanto maior o risco do tratamento médico, maiores devem ser os cuidados com o respeito aos direitos do paciente, principalmente quanto à análise de sua capacidade para decidir. ${ }^{53}$

\footnotetext{
51 "Neither is it obligatory in case of waiver, the patient's voluntary and deliberate giving up of the right to informed consent. It is an exercise in autonomous choice - the choice not to choose or decide. Authority to decide medical issues is turned over to the physician or surrogates." VAUGHN, op. cit., p. 182.

52 "Segundo este critério toma-se a decisão que está de acordo com os melhores interesses do paciente (best interests of the patient), o que se identifica, naturalmente, com a proposta terapêutica do médico. Assim, a aplicação deste standard poderia ser vista como uma ratificação da proposta do médico. Este critério pretende-se objetivo, no sentido de que não se centra nos valores e na personalidade do paciente, mas na sua condição física e no prognóstico traçado, sendo certa que a neutralidade valorativa é meta inalcançável. Hoje em dia, entende-se que nos interesses do paciente devem estar envolvidos não apenas os interesses médicos, mas também o respeito pelos seus valores e pelas suas presumíveis vontades, pelo que, de algum modo, se desenha um "critério sincrético' que combina os dois últimos referidos.” DIAS PEREIRA, op. cit., p. 239.
} 


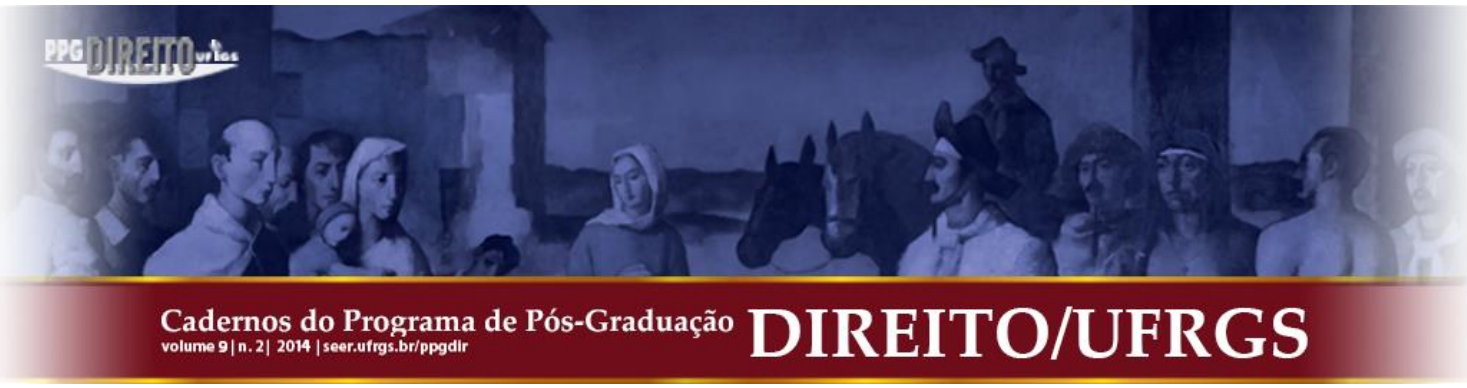

A capacidade decisória é assim, a habilidade para entender os riscos, benefícios e alternativas e para realizar uma decisão razoável.

Mas para que a capacidade decisória seja exercida de forma livre e plena, é necessário que a divulgação da informação seja suficientemente esclarecida.

De logo, verifica-se uma assimetria de informações, pois, sendo o próprio médico que irá fazer o tratamento ou a intervenção cirúrgica, também aquele que irá prestar as informações necessárias, é um tanto lógico que ele fará com que prevaleça em seu discurso a sua vontade, demonstrando uma espécie de paternalismo informativo. ${ }^{54}$

Em 1972, no caso Canterburry v. Spence, a Corte de Apelação do Distrito de Columbia, decidiu que o mais importante em relação aos requisitos do consentimento informado é a sua adequação com o que aparenta ser relevante para o paciente, e não o que possa ser relevante para o pensamento do médico ${ }^{55}$.

O paciente deve receber uma informação adequada com o seu conhecimento e grau de instrução, de modo que possa de forma inteligente analisar os riscos e benefícios do tratamento médico, fazendo a sua melhor escolha.

O melhor método de prestar a informação ainda não está transparente para a doutrina, nem mesmo para os Tribunais, vez que deve variar de caso a caso e de pessoa para pessoa. A mesma doença pode ter pacientes distintos e modos de informar diferentes. Apesar destas dificuldades algumas informações são consideradas básicas para o conhecimento do paciente, segundo a doutrina de Lewis Vaughn:

\footnotetext{
53 "Lo mismo sucede con la capacidad de razonamiento y deliberación. Pero con respecto a ambas cosas vale la idea indudable de que no existe un estándar general de competencia, de forma que pudiéramos decir que dado ciertos rasgos de una persona podemos ya declarar en términos generales si es o no es competente, sino que, muy por el contrario, el grado de competencia de cada uno depende, no sólo de quien es cada uno, sino también de los problemas que tiene ante sí, y en nuestro caso, depende de los problemas de salud sobre los que debe adoptar una decisión. No es lo mismo decidir sobre una cura trivial o un episodio leve de enfermedad conocida (la gripe común, por ejemplo) que decidir sobre una intervención de riesgo." SANMIGUEL, Francisco J. Laporta. Algunas Incógnitas del Principio de Autonomia Personal en Tratamientos Médicos. In: MENDOZA BUERGO, Blanca (Org.). Autonomia Personal y Decisiones Médicas: Cuestione Éticas y Juridicas. Pamplona: Thomson Reuters, 2010, p. 30

54 "Lo paradójico entonces es que para que el paciente ejerza su autonomía a través del consentimiento informado es el médico el que tiene que trasmitirle y trivializarle la información, lo que pude ser visto como una suerte de paternalismo informativo." Ibid. p. 29.

55 " [...] this 1972 case helped settle the question of what standard should be used to judge the adequacy of disclosure by a physician. The court ruled that adequacy should not be judge by what the medical profession thinks is appropiate but by what information the patient finds relevant to his decision. The scope of the communication to the patient 'must be measured by the patient's need, and that need is the information material to the decisión." VAUGHN, op. cit., p. 217.
} 


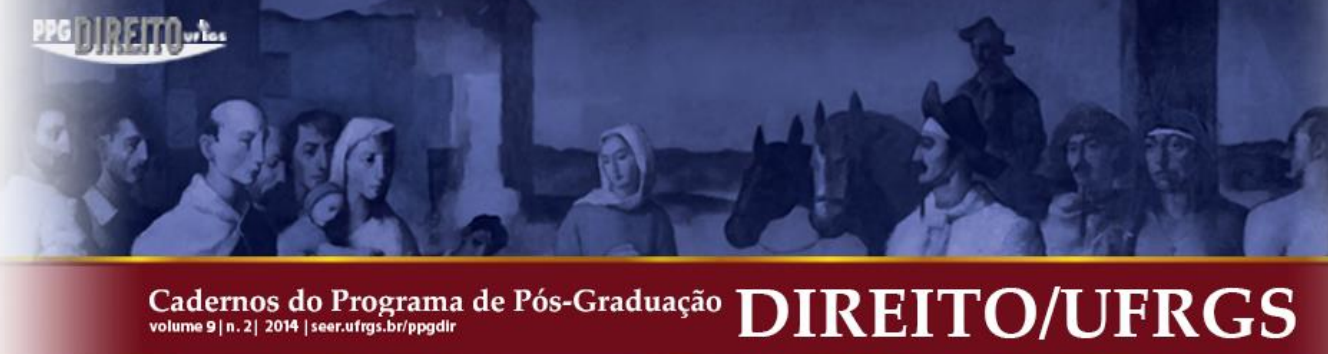

1- A natureza do procedimento (se é um tratamento ou um teste, se é invasivo ou não, se é demorado ou não).

2- Os riscos do procedimento (quais os riscos envolvidos, são riscos prováveis e sérios, qual a sua probabilidade, e quando eles acontecem).

3- Quais as alternativas ao tratamento proposto - inclusive a alternativa de não realizar o tratamento (também inclui sua natureza, riscos e benefícios).

4- Os benefícios esperados quanto ao tratamento proposto - incluindo a sua extensão e possibilidade de ser atingido. ${ }^{56}$

Mas para além da informação exaustiva, podem ocorrer casos em que o melhor para o paciente seja a ignorância parcial do seu problema. Pode ser que a eficácia do tratamento dependa da falta de conhecimento do paciente quanto à realidade do seu problema de saúde.

Desta forma, em alguns casos há exceções ao consentimento informado. Nesse caso, o privilégio terapêutico ${ }^{57}$, consiste em não informar ao paciente quando o médico acredita que a noticia provavelmente irá fazer algum mal. Ou seja, em face da fraqueza do paciente e da possibilidade de uma depressão, a divulgação da informação poderá causar um mal maior. ${ }^{58}$

A informação que deve ser fornecida ao paciente, é assim, aquela necessária para que ele possa apreciar as consequências de sua doença e o tratamento mais adequado para a sua escolha.

Não pode a autonomia ser reduzida ao uma autorização mecânica escrita em um papel, em que o médico visa tão somente libertasse de suas responsabilidades pessoais, em face da possibilidade do tratamento não ocorrer conforme o esperado. ${ }^{59}$

Enfim, há situações em que é impossível para o médico obter o consentimento informado. O próprio Código de Ética ao determinar como essencial para a realização de tratamentos médicos o consentimento informado, excepcionou a sua obrigatoriedade nos casos de risco iminente de morte.

\footnotetext{
56 VAUGHN, op. cit., p. 182.

57 Therapeutic privilege.

58 "Critics worry that too many physicians use therapeutic privilege when they should in fact tell patients the facts and that overuse of it can undo informed consent. In any case, informed consent seems to imply that physicians shouldo not use therapeutic privilege merely to avoid giving unpleasant new sor to prevent them from rejecting a treatment." VAUGHN, op. cit., p. 183.

59 "Un papel además que se firma ya en demasiadas situaciones, tanto si estamos ante un trasplante de hígado como si estamos ante una extracción dental. Seguramente ello no se produce sólo como una estrategia defensiva de la profesión médica, sino también porque, como se ha puesto de manifiesto, tomarse en serio la autonomía del paciente fuerza a entablar con él una relación que consume mucho tiempo y no poca reflexión, y eso es sencillamente imposible en las condiciones actuales de la prestación del servicio público de salud. Quizás en la medicina privada sea posible, pero en la sobrecargada e infradotada organización pública de la salud es sencillamente imposible. De ahí ese contraste sobre el que quería llamar la atención." SANMIGUEL, op. cit. p. 34.
} 


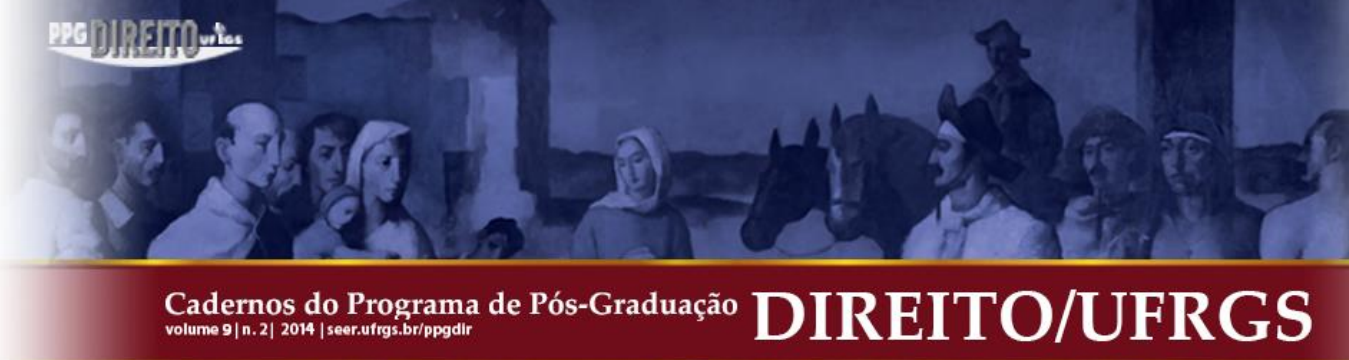

O médico diante de uma situação de emergência, não terá possibilidades de obter o consentimento informado do paciente, haja vista o perigo de morte, devendo intervir de forma que melhor assegure a manutenção da saúde do paciente. ${ }^{60}$

Nesse mesmo sentido, em caso de risco a saúde pública, a liberdade do paciente sofre limitações, diante da situação de conjugação de valores com outras situações de risco, onde está em risco, nesse caso, a saúde de outras pessoas.

O propósito da obrigação de prestar informações e esclarecer ao paciente é dotá-lo de autonomia para poder tomar decisões com relação aos assuntos de saúde e seu tratamento de forma consciente. Assim, para que o consentimento e a recusa sejam válidos ele deve ser baseado na compreensão da situação que se apresenta e deve ser voluntário, pois, este direito está baseado no princípio do respeito à autonomia.

É dever de o médico aconselhar o seu paciente esclarecendo as formas de tratamento e os riscos, e caso o mesmo não queira se submeter ao tratamento indicado, por questões que envolvam o seu próprio convencimento, terá o médico cumprido o seu papel, e ao respeitar a autonomia do paciente estará eticamente protegido.

\section{CONSIDERAÇÕES FINAIS}

O presente trabalho, evidentemente, em face da sua proposta não tem por objeto alcançar todos os aspectos inerentes ao Consentimento Informado, tendo pontuado pelo estudo de alguns pontos críticos, que demonstra a sua jovialidade perante a dinâmica da relação médico-paciente.

Pretende-se fazer uma necessária critica aos casos controversos, a fim de valorizar o consentimento informado, para que ele não seja reduzido simplesmente a uma assinatura em um papel impresso, com o objetivo de liberar o médico e o hospital de suas responsabilidades pessoais e econômicas. ${ }^{61}$

\footnotetext{
60 "As situações de emergência estão neste âmbito, e a decisão deve ser tomada no intuito de obter o melhor prognóstico para o doente. Fala-se, nesta situação, de "consentimento presumido", que pode ser definido como uma situação em que se presume a obtenção do consentimento quando o indivíduo está em perigo de vida, existe comprometimento de saúde ou alteração do estado de consciência, e não é possível obtê-lo junto deste ou de quem o represente (Artigo $39^{\circ}$ do Código Penal Português). Em situações de urgência, em que a não intervenção criaria riscos comprovados para o próprio, considera-se também haver consentimento presumido (artigo $156^{\circ}$ do Código Penal Português)." ENTIDADE Reguladora de Saúde - Consentimento informado - Relatório final. Disponível em: <https://www.ers.pt/uploads/writer_file/document/73/Estudo-CI.pdf>. Acesso em: 9 set. 2014.

${ }^{61}$ SANMIGUEL, op. cit., p. 33.
} 


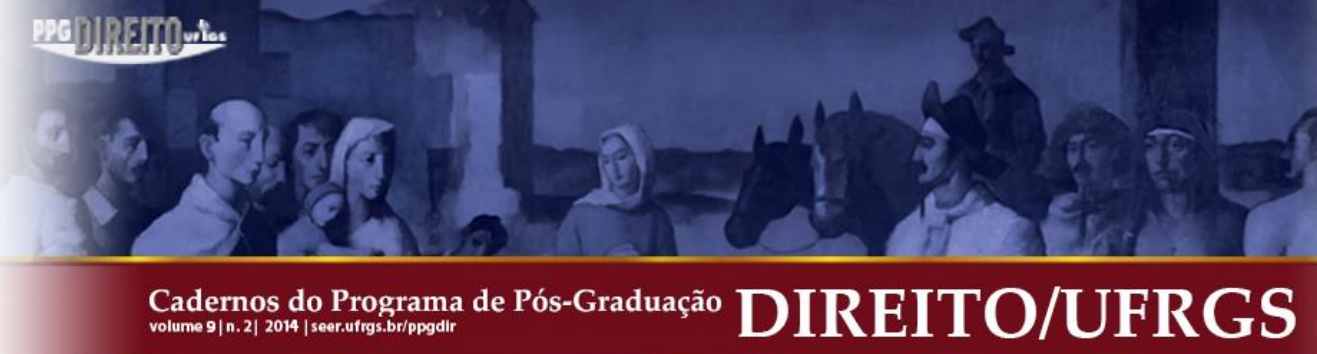

É certo, pode-se concluir que o consentimento informado somente se apresentará como um problema quando a vontade do paciente não vier a coincidir com a expectativa do tratamento médico, aparecendo então a figura do conflito.

Conflitos que não são comuns porque ainda persiste na relação médico-paciente a figura da confiança, que em o paciente declina do seu consentimento informado e transfere para o médico todos os poderes de decisão, diante de uma confiança adquirida durante um longo tempo de convivência. Porém, isto não ocorre nos hospitais públicos e nos casos de urgência, o que demonstra que a capacidade para decidir e o dever de informar, irá depender de cada caso em concreto.

Por sua vez, diante de um conflito entre o médico e o paciente, os motivos do paciente para a recusa do tratamento ou para a realização de tratamento diverso do planejado pelo médico ocorrem, muitas vezes, por questões de convicção do próprio paciente que foge simplesmente a mecânica do tratamento. Ora, muitas vezes o que determina a vontade do paciente são seus valores morais, éticos e religiosos, que se apresentam dentro de uma hierarquia que superam a lógica da ciência médica.

Cabe ao médico respeitar a vontade do paciente, mesmo que suas razões não se apresentem dentro de um contexto de racionalidade. É dever de o médico aconselhar o seu paciente esclarecendo as formas de tratamento, os riscos e suas convicções pessoais, para em seguida obter deste mesmo paciente o seu consentimento esclarecido e informado, e caso o mesmo não queira se submeter ao tratamento indicado, por questões de consciência em face de seus valores, terá o médico cumprido o seu papel, e ao respeitar a autonomia do paciente estará eticamente protegido.

Assim, diferentemente de alguns negócios jurídicos em que a causa e as razões do declarante não são relevantes para a formação do contrato, no caso da relação médico paciente para a manifestação da vontade do paciente, as razões do paciente exercem papel relevante, com enorme significado moral, que permite ao interprete apreciar a liceidade da recusa do tratamento sob outros aspectos diante dos valores do paciente, e não exclusivamente por meio de uma análise cientifica médica.

Com isso, permite-se ainda determinar a sua capacidade e competência para exercer a sua vontade esclarecida. Muitas vezes, a causa não é juridicamente visível, não consta do contrato, não é objeto de manifestação. Porém, em relação ao paciente essas causas somente 


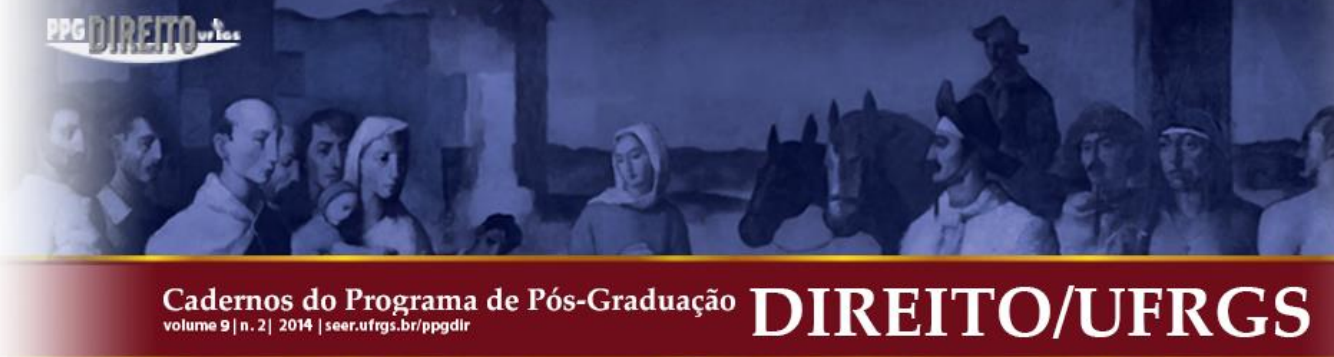

ETHICS in Medicine. University of Washington School of Medicine. Informed Consent: Case 1. Disponível em: <http://depts.washington.edu/bioethx/topics/consntc1.html>. Acesso em: 9 set. 2014.

FERRAZ JR., Tercio Sampaio. Introdução ao Estudo do Direito. 2. ed. São Paulo: Editora Atlas, 1994.

FRANÇA, Genival Veloso. Direito Médico. Rio de Janeiro: Forense, 2013.

JURAMENTO de Hipócrates. Disponível em: <http://www.cremesp.org.br/?siteAcao=Historia\&esc=3> Acesso em: 9 set. 2014.

LEMOS PEREIRA, Paula Moura Francesconi. Relação Médico-Paciente. Rio de Janeiro: Lumen Juris, 2011.

MARTINEZ, Pedro Romano. Responsabilidade Civil por Acto ou Omissão do Médico. In: DUARTE, Rui Pinto; FREITAS, José Lebre de; CRISTAS, Assunção; ALMEIDA, Marta Tavares de; NEVES, Vítor Pereira das (Orgs.). Estudos em Homenagem ao Professor Doutor Carlos Ferreira de Almeida. v. II. Coimbra: Almedina, 2011.

MOTA PINTO, Carlos Alberto. Teoria Geral do Direito Civil. 4. ed. Coimbra: Editora Coimbra, 2012.

OLIVEIRA, Guilherme. Estrutura Jurídica do Acto Médico, Consentimento Informado e Responsabilidade Médica, Temas de Direito da Medicina. Coimbra: Editora Coimbra, 2005.

PEREIRA, Caio Mario da Silva. Instituições de Direito Civil. v. I. 22. ed. Rio de Janeiro: Forense, 2007.

RIESTRA, Sergio Gallego. El Derecho del Paciente a la Autonomia Personal y las Instruciones Previas: uma Nueva Realidad Legal. Navarra: Aranzadi, 2009.

RODRIGUEZ-ARIAS, David. Una Muerte Razonable. Bilbao: Desclée de Brouwe, 2005.

SANMIGUEL, Francisco J. Laporta. Algunas Incógnitas del Principio de Autonomia Personal en Tratamientos Médicos. In: MENDOZA BUERGO, Blanca (Org.). Autonomia 


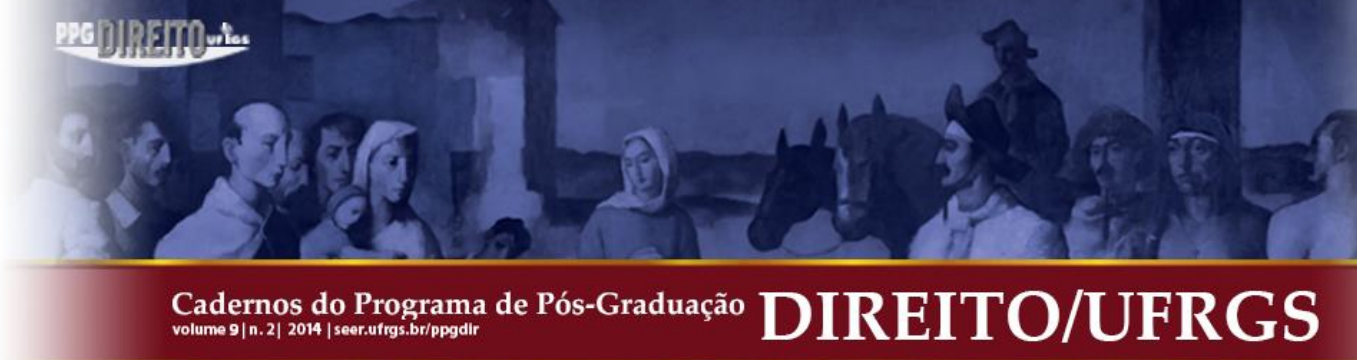

Personal y Decisiones Médicas: Cuestione Éticas y Juridicas. Pamplona: Thomson Reuters, 2010.

SAVULESCU, Julian. Autonomia, vida buena y elecciones controvertidas. In: MENDOZA BUERGO, Blanca (Org.). Autonomia Personal y Decisiones Médicas: Cuestione Éticas y Juridicas. Pamplona: Thomson Reuters, 2010.

SEGRE, Marco; COHEN, Claudio. Bioética. São Paulo: Editora da Universidade de São Paulo, 1995.

SERVAN-SCHREIBER, David. Podemos dizer adeus mais de uma vez. Rio de Janeiro: Fontanar, 2011.

SOUZA, Zelita da Silva; MORAES, Maria Isabel Dias Miorim de. A Ética Médica e o respeito às crenças religiosas. Revista Bioética, v. 6, n. 1, 1998. Disponível em: $<$ http://revistabioetica.cfm.org.br/index.php/revista_bioetica/article/view/329/397>. Acesso em: 9 set. 2014.

VASCONCELOS, Pedro Pais. Teoria Geral do Direito Civil. 3. ed. Coimbra: Almedina, 2005.

Direito de Personalidade. Coimbra: Almedina, 2006.

VAUGHN, Lewis. Bioethics. Principles, Issues, and Cases. New York: Oxford University Press, 2013.

Submissão: 10/09/2014 Aceito para Publicação: 18/12/2014 